\title{
Role of hyperthermic intraperitoneal chemotherapy in ovarian cancer
}

\author{
Juan Manuel Medina-Castro ${ }^{1,2}$, Adriana Ruiz-DeLeón ${ }^{3}$ \\ ${ }^{1}$ Department of Surgical Oncology, Grupo Oncológico de Toluca, Toluca city, Estate of Mexico, Mexico; ${ }^{2}$ Universidad Autónoma del Estado de \\ México, Toluca city, Estate of Mexico, Mexico; ${ }^{3}$ Department of Gynecology, Universidad Autónoma de San Luis Potosí, San Luis Potosí City, State \\ of San Luis Potosí, Mexico \\ Contributions: (I) Conception and design: JM Medina-Castro; (II) Administrative support: All authors; (III) Provision of study materials or patients: \\ All authors; (IV) Collection and assembly of data: All authors; (V) Data analysis and interpretation: JM Medina-Castro; (VI) Manuscript writing: All \\ authors; (VII) Final approval of manuscript: All authors. \\ Correspondence to: Juan Manuel Medina-Castro, MD. Department of Surgical Oncology, Grupo Oncológico de Toluca, colonia Francisco Murguía, \\ Toluca city 50130, Estate of Mexico, Mexico. Email: carcinomatosis.coe@gmail.com.
}

\begin{abstract}
Epithelial ovarian cancer (EOC), has the highest worldwide mortality of all gynecological tumors, in $75 \%$ of cases is diagnosed in advanced stages. Despite of treatments with maximal cytoreductive surgery (CRS) and platinum-based chemotherapy (CT), approximately $70 \%$ of patients with advancedstage disease relapse within 18 months, given this high number of recurrences, new approaches are needed to improve outcomes for these patients. Hyperthermic intraperitoneal chemotherapy (HIPEC) has fundamentally changed the treatment of patients with ovarian cancer, with complete CRS and locoregional administration of chemotherapy. The purpose of this review is to find the most relevant, reliable published evidence of the use of HIPEC in ovarian cancer, together with an overview of peritoneal carcinomatosis (PC), procedures, therapeutic approaches in first-line and recurrent disease, the benefit of hyperthermia, selection of the ideal patient for the HIPEC procedures as well to analyze the disease free survival (DFS), morbidity, mortality and overall survival (OS) in patients with ovary cancer. So far, the small amount of evidence points favorably to the use of CRS and HIPEC as a first line of therapy, but more prospective randomized trials are needed to officially adopt this procedure as a standard of care, additionally patients need to know this option exists.
\end{abstract}

Keywords: Ovarian cancer; hyperthermic intraoperative chemotherapy (HIPEC); prospective; retrospective; rationale; clinical trials

Submitted Jan 31, 2020. Accepted for publication May 08, 2020.

doi: $10.21037 /$ cco-20-49

View this article at: http://dx.doi.org/10.21037/cco-20-49

\section{Introduction}

Epithelial ovarian cancer (EOC) has the highest worldwide mortality (1) of all gynecologic tumors. In $75 \%$ of cases, EOC is diagnosed in advanced stages, III and IV. In the past 20 years, the 10-year survival rate with advanced-stage has ranged from 10 to $15 \%$ without any noticeable change (2). Approximately $70 \%$ of patients with advanced-stage disease relapse within 18 months (3) despite the availability of treatments with maximal cytoreductive surgery (CRS) and platinum-based chemotherapy (3). Historically, peritoneal carcinomatosis (PC) accounts as a damaging cancer, with a very poor prognosis. Therefore, the development of new approaches is critical to improve the outcome for these patients.

The concept of hyperthermic intraoperative chemotherapy (HIPEC) was introduced by Spratt et al. from Louisville, KY in 1980 (4). In 1983 the pharmacologic advantages of intraperitoneal drug delivery were exposed by Dedrick plots (5), Koga et al. (6) studied the physiology of HIPEC with mitomycin C (MMC) in gastric cancer, Gilly et 
al. showed the possible benefits of hyperthermia regarding the surgical procedure. The description of peritonectomy is a contribution from Professor Sugarbaker (7). Researchers from all over the world, specially France (8), Italy (9), Japan (10), Latin-America (11), Australia (12), UK (13), Greece (14), Deutschland (15) and Spain (16), are investigating and using CRS and HIPEC as the relatively new standard treatment for PC (17). The 40-year evolution of a "new" and successful multidisciplinary treatment strategy for PC it is an indisputable fact (18). The attempt in this review, is to classify patients in the following groups according to their therapeutic approach (first-line treatment, with or without neoadjuvant chemotherapy (NACT), progression, and recurrence under platinum sensitive or resistant cancer) and thus obtain the most reliable information for each moment of the disease.

\section{Basis of HIPEC}

CRS (currently defined as complete macroscopic resection), in addition of systemic chemotherapy (CT) with a platinum-taxane-based compound, is the standard treatment of advanced ovarian cancer (19). Regardless of cancer recurrence, the disease remains limited to the peritoneal cavity for a long time, which represents an optimal target for aggressive regional treatments (20). Loco-regional administration of CT increases the concentration of the chemotherapeutic agent at the site of action, reducing the systemic toxicity of the intravenous (IV) treatment, with the disadvantage of increased postoperative morbidity due to the surgical procedure.

Tumor cells in contrast to normal tissue, can be irreversibly damaged when exposed to high temperatures, by several action mechanisms that in combination with CT increase cancer cells mortality rates.

\section{Physiopathology of carcinomatosis}

In the past, it has been assumed that intra peritoneal (IP) cancer dissemination is a random process. However, observations have suggested patterns of cancer cell dissemination by contiguity, but discontinuous. That is, it remains only in the peritoneal cavity, but not as a progressive growing tumor or plaque from the malignancy primary site (21).

Directions taken by detached cancer cells within the peritoneal cavity may be affected by factors including: anatomic site of the primary tumor, histologic type, changes in intra-abdominal pressure, gravity, peristalsis, peritoneal adhesions, fibrin entrapment from trauma during a surgical intervention, resorption, viscosity and volume of peritoneal fluid (22).

\section{Peritoneum basics}

(I) Physiopathology of peritoneal dissemination starts with the loss of cell-adhesion from the primary tumor in order to migrate to distant sites. Then, released tumor cells exhibit decreased adhesion and enhanced motility; (II) once the cells are inoculated in the peritoneal cavity, distribution throughout the abdomen begins, directed by three basic forces: gravity, peristalsis, and negative pressure exerted by the thorax and diaphragm movements; (III) successive IP metastasis takes two routes denominated, trans-mesothelial and trans-lymphatic; (IV) the cytokines IL (interleukins), epidermal growth factor (EGF), hepatocyte growth factor (HGF), vascular endothelial growth factor-C (VEGF-C) influences the contraction of mesothelial cells, thereby exposing the sub-mesothelial basal membrane; (V) allowing tumor cells to adhere through the interaction of integrins; (VI) also degrading the peritoneal blood barrier assisted by matrix metalloproteinases (MMPs), and (VII) other motility factors (23-26) (Figure 1).

\section{Cytoreduction/peritonectomy}

\section{First line treatment at FIGO stages III and IV}

The earliest evidence to support CRS, came from Griffiths' retrospective review (1975). In the most recently published study by Biacchi et al. (27), two study groups were compared, first one with CRS and HIPEC, second one with NACT followed by CRS and HIPEC as a first-line treatment. Their results reported similar outcomes in both groups regarding PFS of 29.5 months (95 \% CI, 25.89-NA months) versus 20.3 months (95\% CI, 15.2-28.3 months). Moreover, the OS analysis showed improved outcomes, although not significantly better, in patients who underwent up front surgery than in those in the second group with a median month of OS not reached in the first group $v s$. 51.5 months (95\% CI, 33.9-NA months), in the second group. This study draws attention to the better outcomes in patients with complete CRS [Complete Cytoreduction (CC) Score 0], within PFS or OS. The cox univariate analysis showed that patients who underwent CRS with residual disease had approximately $20 \%$ higher risk of recurrence than those without residual disease (HR, 1.209, 


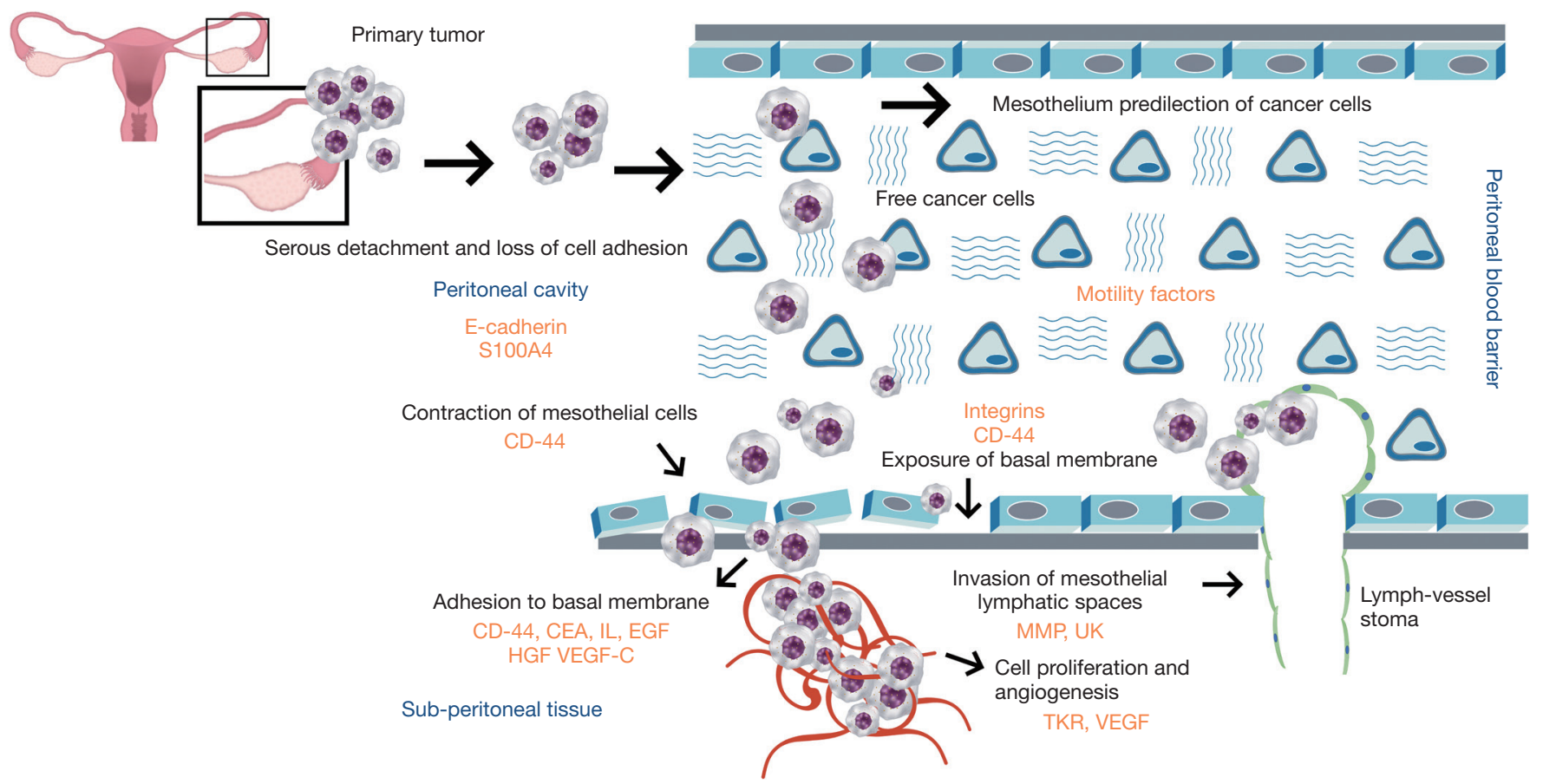

Figure 1 Physiopathology of carcinomatosis.

95\% CI, 0.7764-1.882) with increased likelihood of death approximately $50 \%$ (HR, 1.562, 95\% CI, 0.9332-2.614) $(27,28)$. Bristow's 2006 meta-analysis (22 cohorts with 835 patients) stated that the best first-line ovarian cancer approach is the optimal cytoreduction, these data being corroborated by Dennis S. Chi, GOG 52, 97, and Karin K. Shih.

The "HIPECOVA" study by Campos et al., evaluated the use of HIPEC with paclitaxel (PTX) for patients with recurrent or primary advanced EOC, with two study arms, first: CRS + HIPEC with PTX, followed by postoperative systemic CT with carboplatin (CBDCA) + PTX, and second: CRS followed by postoperative systemic CT with CBDCA + PTX. Their primary outcome measures are OS and PFS, but results are pending to be published. (NCT02681432) (Apendix 1).

\section{Interval CRS-neoadjuvant treatment (NACT)}

The name NACT has been portrayed in two different perceptions: number one, is the implementation of CT, after cancer confirmation through just biopsies, following several courses of this systemic therapy, CRS is attempted in the course of an interval laparotomy. Number two is the CT applied after a suboptimal debulking tumor surgery, followed by a CRS called interval CRS, this approach more commonly called as induction therapy, but has also been named 'neoadjuvant' (29).

The concept of primary CT with a posterior interval debulking CRS, has arisen mainly because optimal cytoreduction can only be achieved in $35-50 \%$ of women with advanced EOC (30). And without optimal cytoreduction, prognosis at a 5-year survival rate will be of approximately $15 \%$, independent of the residual tumor extension (31).

Ignace Vergote in 2010 stablished the use of neoadjuvant $\mathrm{CT}$ as an optimal treatment option in patients with ovarian cancer stage IV (vergote y CHORUS).

The advantages of surgery after NACT are: less intraoperative blood loss, shorter operative time, fewer intensive care unit (ICU) admissions, and a shorter hospital length of stay (LOS). This is especially relevant in countries with limited resources on ICU care, hemotransfusion capacity and advanced post-surgical care measures (32). NACT used for two or three cycles may reduce disease load and improve tumor resectability. Cascales-Campos et al. stated that patients with NACT plus complete CRS and HIPEC were associated with a prolonged PFS in all subgroups except those with undifferentiated tumors, compared to control arm of patients without HIPEC $(33,34)$.

The main study on NACT and HIPEC is a work of 
van Driel et al., concluding that the addition of HIPEC to interval CRS showed longer recurrence-free survival (RFS) and OS than surgery alone, without resulting in higher rates of side effects. The median RFS was 10.7 months in the surgery group and 14.2 months in the surgery-plusHIPEC group. The median OS was 33.9 months in the surgery group and 45.7 months in the surgery-plus-HIPEC group (35).

In this context, there is a phase III clinical trial, the CHORINE study, by Ansaloni et al., assessing HIPEC as upfront treatment of stage IIIC EOC, where they compared unresectable disease, with a partial or complete response after 3 cycles of first line CT (CBDCA + PTX) followed by CRS and HIPEC, with CDDP + PTX versus CRS alone, their results are still pending to be published. (NCT01628380) (Apendix 1).

\section{Recurrent disease}

Throughout history, the use of HIPEC in any cancer has been subjected as the introduction of a new therapy inaugurated by the patients with the most unfavorable prognosis, poor outcomes in spite of multiple lines of systemic chemotherapy, with the attempt to rescue them from an imminent death. It is challenging to assess an objective response on recurrent disease together with the comparability between studies, groups and patients; nevertheless, results have been consistently the same, there is a benefit in patients treated with HIPEC.

Obstacles in establishing HIPEC as a standard of care in ovarian cancer have been the discrepancies between studies and published data where patients are included in noncomparable groups. This leaves an unclear role in first-line treatments with or without NACT, or if the studied patients were sensible to platinum agents or non-responders, and in their final analysis there is lack information about OS and DFS or if patients were on their first or second recurrence.

Whereas the beneficial impact of CRS is clear in the first line treatment, it is less evident in the treatment of patients with recurrent disease. Undoubtedly patients with a good performance status, a prolonged disease-free interval, a low carcinomatosis index, an absence of ascites, and optimal cytoreduction are the best candidates for the use of HIPEC (36).

In 2004, Ryu et al. pointed the benefit of HIPEC on the recurrent-disease patient group (37). Adding HIPEC to the present treatment modalities for recurrent ovarian cancer seems to improve survival rates in some series, with an acceptable mortality rate, but at the cost of significant morbidity rates during the first few years of the surgical learning curve. The beneficial impact of secondary cytoreduction in the treatment of recurrent disease has not been fully elucidated. Available data, reports consistent survival rates using the combined treatment approach on patients with recurrent EOC (38-47).

In that respect, the CHIPOR study which is an ongoing phase III, European multicentric randomized trial by Classe et al., treating patients in their first relapse of EOC, starting with 2 types of second line intravenous chemotherapy (IVCT), if there is a favorable response, and CRS seems possible, 5 to 8 weeks later patients will be randomized to either treatment A, maximal CRS without HIPEC or B: maximal CRS with HIPEC, with the goal to improve the median OS by 12 months after the patient's first relapse; results have not yet been described. (NCT01376752) (Apendix 1).

There are more retrospective studies with comparison between first-line therapy and recurrent disease, showed in Table 1. Prospective studies that describe recurrent disease results, Cotte 2007 (40), Muñoz-Casares 2009 (48), Ansaloni 2012 (45), Gonzalez Bayon 2013 (44) are showed in Table 2.

\section{Pharmacokinetics and pharmacodynamics of drugs}

Hyperthermia is known to enhance cytotoxicity and improve the penetration depth of some cytostatic drugs (49). Conclusions from studies have given us information about the area under the curve (AUC) of intraabdominal used doses, exposure time of Melphalan, Mitomycin C and CDDP as well as the expected toxicity (50-52).

The data obtained from these studies have set the standard for their use, but it has been remarkably challenging to assume they are completely valid, due to the multiple factors that affect the results, i.e., the complexity of establishing the desirable drug concentration (53).

So, the rationale for IP drug administration is supported by preclinical and pharmacokinetic data; Armstrong et al., showed a considerable toxicity with the administration of normothermic IP CDDP in association with PTX (54). In the hyperthermia studies this is not observed when CDDP is administered alone or in association with MMC which is favorable for maintaining peritoneal drug concentration at therapeutic levels.

Hyperthermia is found to be a powerful modulator of CDDP cytotoxicity, both in sensitive and resistant ovarian cancer cells. Relatively high heat doses $\left(43^{\circ} \mathrm{C}\right.$ during $60 \mathrm{~min}$ ) appear to specifically interfere with CDDP cell 
Table 1 Retrospective HIPEC scientific evidence

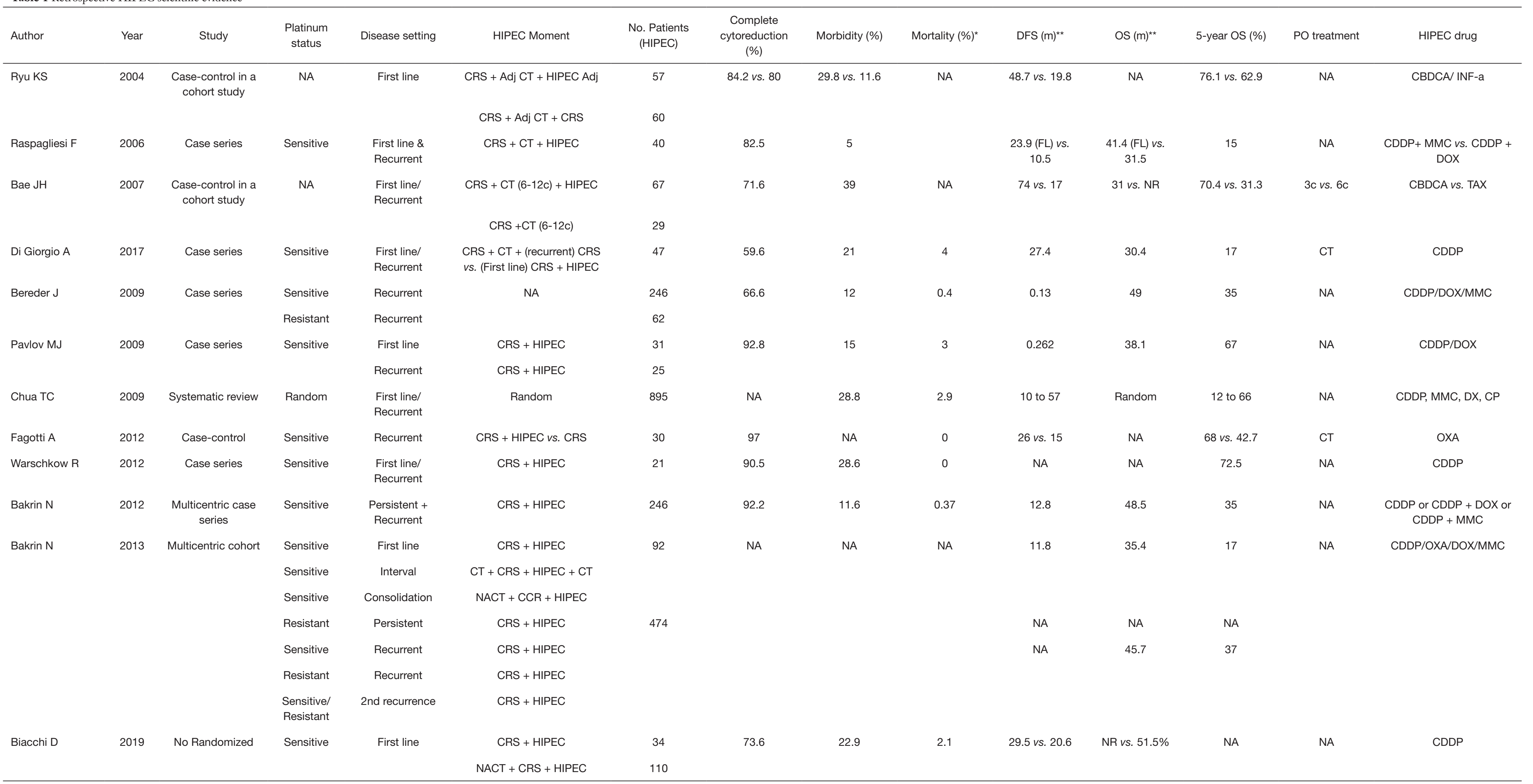

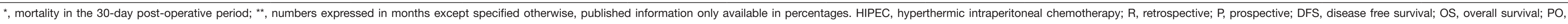

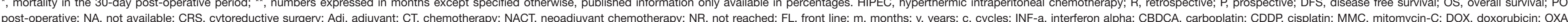
oxaliplatin. Abbreviations according to the National Cancer Institute drug dictionary. Available online: https://www.cancer.gov/publications/dictionaries/cancer-drug 
Table 2 Prospective HIPEC scientific evidence

\begin{tabular}{|c|c|c|c|c|c|c|c|c|c|c|c|c|c|c|}
\hline Author & Year & Study & $\begin{array}{l}\text { Platinum } \\
\text { status }\end{array}$ & Disease setting & HIPEC Moment & $\begin{array}{l}\text { No. Patients } \\
\text { (HIPEC) }\end{array}$ & $\begin{array}{l}\text { Complete } \\
\text { cytoreduction } \\
(\%)\end{array}$ & Morbidity (\%) & Mortality $(\%)^{*}$ & $\operatorname{DFS}(m)^{* *}$ & OS $(\%)^{* *}$ & 5-year OS $(\%)^{\wedge}$ & PO treatment & HIPEC drug \\
\hline \multirow[t]{2}{*}{ Cotte E } & 2007 & Case series & $\begin{array}{l}\text { Sensitive/ } \\
\text { Resistant }\end{array}$ & Chemoresistant & CRS + HIPEC & 81 & 55.5 & 13.6 & 2.5 & 19.2 & 28.4 & NA & CT & CDDP \\
\hline & & & & $\begin{array}{l}\text { Second } \\
\text { recurrence }\end{array}$ & & & & & & & & & & \\
\hline \multirow[t]{2}{*}{$\begin{array}{l}\text { Muñoz-Casares } \\
\text { FC }\end{array}$} & 2009 & Case series & Sensitive & & $\begin{array}{c}\text { CRS }+ \text { CT + (recurrent) CRS/ } \\
\text { HIPEC }\end{array}$ & 14 & 64 & 29 vs. 25 & NA & $\begin{array}{c}48 \pm 42 \text { vs. } \\
24 \pm 21\end{array}$ & $67 \%$ vs. $29 \%$ & 67 & $\begin{array}{c}6 c(C D D P \text { or } \\
\text { CBDCA + TAX) }\end{array}$ & TAX \\
\hline & & & & & CRS + CT + (recurrent) CRS & 13 & & & & & & & & \\
\hline Guardiola E & 2009 & Case series & Sensitive & First line & $\begin{array}{c}\mathrm{CT}+\mathrm{CSR} \text { (HIPEC) vs. CRS } \\
\text { (HIPEC) }\end{array}$ & 47 & 57 & 77 & & 14 & NA & NA & $\mathrm{CBDCA}+\mathrm{TAX}$ & CDDP \\
\hline Pomel C & 2010 & Non-randomized & Sensitive & Consolidation & $\mathrm{CRS}+\mathrm{CT}+\mathrm{HIPEC}$ & 28 & NA & 46.4 & NA & NA & 0.67 & NA & NA & OXP \\
\hline Deraco M & 2011 & Case series & Sensitive & First line & CRS + HIPEC & 26 & 56.6 & 15 & 4 & 30 & NA & 60.7 & $\begin{array}{l}\text { 6c (CBDCA + } \\
\text { TAX) }\end{array}$ & CDDP + DOX \\
\hline Ansaloni L & 2012 & Randomized & Sensitive & $\begin{array}{l}\text { First line/ } \\
\text { Recurrent }\end{array}$ & CRS + HIPEC vs. CRS & 39 & 90 & 18 & NA & 11.7 & 36 & NA & CT & $\begin{array}{l}\text { CCDP +TAX vs. } \\
\text { CDDP +DOX }\end{array}$ \\
\hline \multirow{3}{*}{$\begin{array}{l}\text { Gonzalez } \\
\text { Bayon L }\end{array}$} & 2013 & 0 & Sensitive & First line & CRS + HIPEC & 15 & 73 & 26 & 2 & 21.1 & 0.72 & 77.8 & NA & CDDP + DOX \\
\hline & & Case series & & Recurrent & CRS + HIPEC & 19 & 74 & 26 & 1.9 & 18.1 & 0.622 & 62.8 & NA & $\mathrm{CDDP}+\mathrm{DOX}$ \\
\hline & & & & $\begin{array}{l}\text { Second } \\
\text { recurrence }\end{array}$ & CRS + HIPEC & 8 & 75 & 26 & 0.8 & 5.7 & 0.179 & 35.7 & NA & CDDP + DOX \\
\hline \multirow[t]{2}{*}{ Spiliotis J } & 2015 & Randomized & $\begin{array}{l}\text { Sensitive/ } \\
\text { resistant }\end{array}$ & Recurrent & CRS + HIPEC & 60 & 65 & NA & NA & NA & 26.7 & NA & NA & CCDP + TAX \\
\hline & & & & & CRS + CT & 60 & 65 & NA & NA & NA & 13.4 & NA & NA & $\mathrm{DOX}+\mathrm{TAX}$ or MMC \\
\hline \multirow[t]{4}{*}{ Lim MC } & 2017 & Randomized & Sensitive & First line & CRS + HIPEC & 92 & 1 & NA & 0 & 0.209 & 0.51 & NA & NA & CDDP \\
\hline & & & & & NACT + CRS + HIPEC & & & & & 0.372 & 0.479 & & & \\
\hline & & & & & NACT + CRS & 92 & & & & 0.295 & 0.277 & & & \\
\hline & & & & & CRS & & & & & 0.16 & 0.494 & & & \\
\hline \multirow[t]{2}{*}{ Van Driel W } & 2018 & Randomized & Sensitive & First line & $\mathrm{NACT}+\mathrm{CRS}$ & 123 & 67 & 25 & & $\begin{array}{c}10.7 \% \text { vs. } \\
14.2 \%\end{array}$ & $\begin{array}{c}33.9 \% \text { vs. } \\
45.7 \%\end{array}$ & NA & NA & CDDP \\
\hline & & & & & NACT + CRS + HIPEC & 122 & 69 & 27 & & & & & & \\
\hline
\end{tabular}

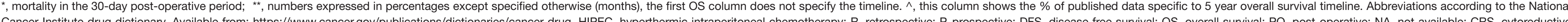

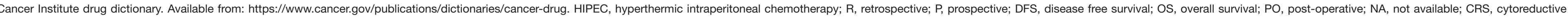
surgery; Adj, adjuvant; CT, Chemotherapy; NACT, neoadjuvant chemotherapy; NR, not reached; FL, front line; m, months; y, years; c, cycles; INF-a, interferon alpha; CBDCA, carboplatin; CDDP, cisplatin; MMC, mitomycin-C; DOX, doxorubicin; OXA, oxaliplatin. 
resistance, this mechanism has not been fully elucidated. The following proposed mechanisms of resistance to CDDP are mostly a result from the studies by Hetting et al.: drug accumulation, decreased detoxification, increased CDDP-DNA adduct formation, reduced DNA repair, and modulation of CDDP resistance. The intention of HIPEC treatment is to reverse, avoid or modify these mechanisms in order to achieve response rates that grant the patient prolonged RFS, this is also demonstrated in a study by Spiliotis et al. (14).

\section{Hyperthermia}

In vivo tumor cells in contrast to normal tissue, can be irreversibly damaged when exposed to temperatures between $40^{\circ}$ and $44^{\circ}$, due to the tumor's physiological characteristics. The vessel distribution of solid tumors is chaotic and inadequate, mediating hypoxic and acidic regions (55) making cells more vulnerable to the hyperthermia treatment. With temperatures after $42.5-43{ }^{\circ} \mathrm{C}$ and time of exposure, are contributing factors to the hyperthermia therapy efficacy. Most normal tissues remain unaffected even after an exposure of 1 hour at a temperature of up to $44^{\circ} \mathrm{C}(56)$. The central cell death mechanism with hyperthermia is protein denaturation, observed at temperatures $>40{ }^{\circ} \mathrm{C}$, altering structures like the cytoskeleton and cell membranes, affecting DNA synthesis and repair mechanisms (57). Several studies have used hyperthermia treatment alone, one series of 343 patients reported complete response rates varying from $0 \%$ to $40 \%$ (overall $13 \%$ ) and partial response rates from $0 \%$ to $56 \%$, with an overall objective response rate of $51 \%$. Along the same line, three additional studies report complete response rates of $11 \%, 16 \%$ and $18 \%$ respectively $(4,58)$.

\section{Selection of the ideal patient}

Nowadays, we don't have a randomized clinical prospective trial that gives us the best explanation to select the ideal patient. We utilize the following scores as a tool for patient selection, taking in to consideration all three of them added to the oncological team experience in order to obtain the maximal benefit for the patient, which is optimal cytoreduction, less morbidity, no postoperative mortality, increase in PFS and OS.

\section{Peritoneal carcinomatosis index (PCI)}

The tumor volume found at the time of surgery has proven to be a prognostic factor and allows preparation of treatment schemes, the following have been published:

The Gilly PC staging (59), the Simplified Peritoneal Cancer Index (SPCI), mostly used for colorectal and appendiceal cancer staging with a prognostic implication for survival, following CRS and HIPEC (60). The Peritoneal Cancer Index (PCI), which was initially used for the evaluation of carcinomatosis of gastrointestinal origin (61). In EOC is determined at the time of surgical exploration, functioning as a complete cytoreduction probability estimate and has been shown to be an accurate assessment survival tool with the treatment combination of CRS and HIPEC (62). With the advantageous, ease of use and accuracy to correlate with the possibility of optimal cytoreduction and OS has directed its examination in ovarian cancer, also obtaining an extraordinary correlation (63-65).

\section{Peritoneal Surface Disease Severity Score (PSDSS)}

The development of tools capable of defining more clearly the current status of an individual, based on preoperative clinical characteristics not only helps us to improve patient selection who will benefit from the HIPEC procedure, but also to discuss the possible risks with patients (66). PSDSS was developed to prospectively stratify patients [based on (I) symptoms, (II) disease extent (CT-assisted PCI), and (III) histology], evaluated with peritoneal disease from colon cancer, and on a multivariate analysis was found to be a prognostic predictor of survival $(67,68)$.

Due to the effectiveness of the score in colon cancer, PSDSS was performed by Esquivel et al. in patients with carcinomatosis taken to HIPEC treatment in ovarian cancer. Patients with score of I/II, showed a survival advantage over patients stratified as III/IV regardless of therapy, 100 versus 55 (68). In the original paper (for colon cancer) patients were stratified according to; (I) symptoms, described from none to severe, (II) the PCI, from less than 10 to more than 20, (III) histology type/tumor differentiation. In the ovarian paper, the PSDSS score obtained a $\mathrm{P}$ value of 0.001 between groups. An important point worth mentioning is that the presence of signet ring cells is extremely rare in ovarian cancer, so it would be worth to study patients whose histological findings present clear cells instead.

\section{Fagotti index}

Therefore, knowing if we can take patients to complete cytoreductions (CCR0) is crucial. Diagnostic image studies (69) 
have shown failures in this regard to calculate the PCI, or establish the severity score; for this reason, Fagotti et al. designed a laparoscopic evaluation. this calculates with greater certainty, avoids unnecessary laparotomies and helps to start earlier with systemic therapy. Eight laparoscopic features are assessed as potential indicators of surgical outcome; (I) the presence of ovarian masses (unilateral or bilateral), (II) omental cake or bulky lymph nodes, (III) PC, (IV) extensive carcinomatosis of the diaphragm, (V) mesenteric retraction, (VI) bowel infiltration, (VII) stomach infiltration, (VIII) liver metastasis (70-72). This index it's the most practical one to understand what is happening in the peritoneum. Eighty-seven percent of the candidate patients for debulking according to this index had optimal cytoreduction, only $13 \%$ did not, and this was due to the presence of retroperitoneal disease. Since her pilot study was published, this index has displayed the feasibility, accuracy and efficacy needed to assess whether the patient could be a candidate for optimal cytoreduction with a (PPV) positive predictive value and a (NPV) negative predictive value between $80 \%$ and $100 \%$.

\section{Worldwide experience with the use of HIPEC}

The tables above, depict the highly relevant published studies with evidence that supports our daily practice, the majority showing a beneficial effect of HIPEC use in ovary cancer. Nevertheless it is to be noted that the reason why HIPEC has not been established as a standard of care in ovarian cancer is a attributable to the discrepancies between published data, with non-comparable patient groups, unclear first-line treatments with or without NACT, not stating if the patients were sensitive to platinum agents or non-responders, furthermore the available results of OS and DFS lack information about timing, meaning if patients are on their first or second recurrence, which continues to be a drawback in this field of research. For the retrospective data $(28,34,37,38,72-80)$, for prospective data $(27,35,36,40,44,45,48,81,82)$ (Tables 1,2$)$.

\section{Quality of life (QoL)}

For many years, the measurement of the QoL in patients undergoing a HIPEC procedure, was not a fundamental objective, the first pursued information in a new treatment is to find usefulness with respect to DFP and OS.

QoL returns to a primary objective with the evidence of treatment benefits, now in published studies describing the patient's point of view, outlining if the benefits outweigh the risks and qualifying if the discomfort presented is compensated or bearable when compared to the benefit of being alive. In 2013, Tan et al. (83), describes QoL based on the European Organization for Research and Treatment of Cancer (EORTC) questionnaires for ovarian cancer, as well as Chia et al. (84), Piso et al. (85), or Koole et al. (86). (OVHIPEC trial), described that in $80 \%$ of patients there were no changes in QoL after 6-16 months of HIPEC treatment and denote a clear improvement in cognitive function and fatigue caused by peritoneal disease $(\mathrm{P}=0.014$ and 0.04 , respectively). Not much information in this regard is available, but it is also true that every day patients are grateful for these improvements, which, together with surviving a little longer, are the goal of our medical management (86-88).

\section{Cost-benefit}

It is apparent that the expense of the HIPEC procedure is by far less expensive than any current systemic CT for ovarian cancer (bevacizumab, olaparib, niraparib or rucaparib), it is also clear that systemic therapies are ineffective for PC. There are few studies in this field, mostly with non-encouraging results, yet the surgical community are motivated to keep going due to clinical improvement, the increase in DFS and OS. Adding up these aspects together toward a specific patient, we observe how a small window of opportunity transforms in a big door where the patient can comfortably pass.

The costs of a HIPEC procedure can not only be accounted as the intraoperative costs, since the post-surgical costs can be more significant, depending on the length of stay in the ICU, which is variable in every patient, some don't require it and some can stay in the ICU up to 30 days if presented with complications such as pneumonia, pleural effusion, kidney failure, surgical wound infection, anastomosis dehiscence, stomata, hydro electrolytic abnormalities, and cardiac or hematological complications (89-91).

The benefit of the HIPEC procedure when compared to systemic therapies, is that it only needs to be performed once, unlike systemic therapies used as the only treatment modality involve not only the expense of the drug itself, premedication as support therapy to avoid chemotherapy adverse effects, also the expense of hospital transport every time it needs to be administered, and this cost is not only for one person, as generally patients are accompanied by a significant other who had to stop a working day or daily 
activities to assist the patient receiving the therapy. All these expenses are not commonly appreciated, but have a longterm impact on therapeutic adherence (92-96).

\section{Conclusions}

In a 2002 editorial in the Fournal of Clinical Oncology, Alberts et al. (97) stated, "We cannot think of any other setting in oncology where the results of three positive phase III trials have not led to widespread adoption of the superior therapy. The time has come for IP chemotherapy to move beyond the setting of clinical trials and into the standard treatment armamentarium for women with optimally debulked stage III ovarian cancer, we owe our patients nothing less." That being said, our task is to look forward, not backwards, in terms of how we can prolong the lives of these extremely courageous women with advanced ovarian cancer who fight every day to stay alive.

The discussion of whether one treatment is better than another, should not fit into this gynecological neoplasm, which, historically is the deadliest. the discussion should emphasize in what treatment sequence will break the $50 \% 5$-year survival rate barrier, as well as the $80 \%$ of recurrences and the $94 \%$ of 10 -year mortality for these patients. Adding is far better than arguing.

\section{Acknowledgments}

We thank the two anonymous reviewers whose comments/ suggestions helped improve and clarify this manuscript. Funding: None.

\section{Footnote}

Provenance and Peer Review: This article was commissioned by the Guest Editor (Heriberto Medina-Franco) for the series "Ovarian Cancer" published in Chinese Clinical Oncology. The article was sent for external peer review organized by the Guest Editor and the editorial office.

Conflicts of Interest: The authors have completed the ICMJE uniform disclosure form (available at http://dx.doi. org/10.21037/cco-20-49). The series "Ovarian Cancer" was commissioned by the editorial office without any funding or sponsorship. The authors have no other conflicts of interest to declare.

Ethical Statement: The authors are accountable for all aspects of the work in ensuring that questions related to the accuracy or integrity of any part of the work are appropriately investigated and resolved.

Open Access Statement: This is an Open Access article distributed in accordance with the Creative Commons Attribution-NonCommercial-NoDerivs 4.0 International License (CC BY-NC-ND 4.0), which permits the noncommercial replication and distribution of the article with the strict proviso that no changes or edits are made and the original work is properly cited (including links to both the formal publication through the relevant DOI and the license). See: https://creativecommons.org/licenses/by-nc-nd/4.0/.

\section{References}

1. Siegel RL, Miller KD, Jemal A. Cancer statistics, 2019. CA Cancer J Clin 2019;69:7-34.

2. Siegel R, Naishadham D, Jemal A. Cancer statistics, 2013. CA Cancer J Clin 2013;63:11-30.

3. Koole SN, van Lieshout C, van Driel WJ, et al. Cost Effectiveness of Interval Cytoreductive Surgery With Hyperthermic Intraperitoneal Chemotherapy in Stage III Ovarian Cancer on the Basis of a Randomized Phase III Trial. J Clin Oncol 2019;37:2041-50.

4. Spratt JS, Adcock RA, Muskovin M, et al. Clinical delivery system for intraperitoneal hyperthermic chemotherapy. Cancer Res 1980;40:256-60.

5. Boxenbaum H, Ronfeld R. Interspecies pharmacokinetic scaling and the Dedrick plots. Am J Physiol 1983;245:R768-75.

6. Koga S, Hamazoe R, Maeta M, et al. Prophylactic therapy for peritoneal recurrence of gastric cancer by continuous hyperthermic peritoneal perfusion with mitomycin C. Cancer 1988;61:232-7.

7. Gilly FN, Sayag AC, Carry PY, et al. Intra-Peritoneal Chemo-Hyperthermia (CHIP): a new therapy in the treatment of the peritoneal seedings. Preliminary report. Int Surg 1991;76:164-7.

8. Elias D, Gilly F, Boutitie F, et al. Peritoneal colorectal carcinomatosis treated with surgery and perioperative intraperitoneal chemotherapy: Retrospective analysis of 523 patients from a multicentric french study. J Clin Oncol 2010;28:63-8.

9. Deraco M, Kusamura S, Virzì S, et al. Cytoreductive surgery and hyperthermic intraperitoneal chemotherapy as upfront therapy for advanced epithelial ovarian cancer: Multi-institutional phase-II trial. Gynecol Oncol 
2011;122:215-20.

10. Yonemura Y, Sako S, Wakama S, et al. History of Peritoneal Surface Malignancy Treatment in Japan. Indian J Surg Oncol 2019;10:3-11.

11. Latin American Registry of Peritoneal Diseases - LARPD participants. Current practice of Latin American centers in the treatment of peritoneal diseases with cytoreductive surgery with HIPEC. Eur J Surg Oncol 2018;44:1800-4.

12. Farrell R, Liauw WS, Brand AH. Ovarian Cancer Surgery in Australia and New Zealand: A Survey to Determine Changes in Surgical Practice over 10 Years. Int J Gynecol Cancer 2018;28:945-50.

13. Moran BJ. Establishment of a peritoneal malignancy treatment centre in the United Kingdom. Eur J Surg Oncol 2006;32:614-8.

14. Spiliotis J, Halkia E, Lianos E, et al. Cytoreductive Surgery and HIPEC in Recurrent Epithelial Ovarian Cancer: A Prospective Randomized Phase III Study. Ann Surg Oncol 2015;22:1570-5.

15. Verwaal VJ, Bruin S, Boot H, et al. 8-Year follow-up of randomized trial: Cytoreduction and hyperthermic intraperitoneal chemotherapy versus systemic chemotherapy in patients with peritoneal carcinomatosis of colorectal cancer. Ann Surg Oncol 2008;15:2426-32.

16. González-Moreno S. Hyperthermic intraperitoneal chemotherapy: Rationale and technique. World J Gastrointest Oncol 2010;2:68.

17. Bushati M, Rovers KP, Sommariva A, et al. The current practice of cytoreductive surgery and HIPEC for colorectal peritoneal metastases: Results of a worldwide web-based survey of the Peritoneal Surface Oncology Group International (PSOGI). Eur J Surg Oncol 2018;44:1942-8.

18. Sugarbaker PH. Evolution of cytoreductive surgery and perioperative intraperitoneal chemotherapy for peritoneal carcinomatosis: Are there treatment alternatives? Am J Surg 2011;201:157-9.

19. Hennessy BT, Coleman RL, Markman M. Ovarian cancer. Lancet 2009;374:1371-82.

20. Bakrin N, Classe JM, Pomel C, et al. Hyperthermic intraperitoneal chemotherapy (HIPEC) in ovarian cancer. J Visc Surg 2014;151:347-53.

21. Coccolini F, Gheza F, Lotti M, et al. Peritoneal carcinomatosis. World J Gastroenterol 2013;19:6979-94.

22. Carmignani CP, Sugarbaker TA, Bromley CM, et al. Intraperitoneal cancer dissemination: mechanisms of the patterns of spread. Cancer Metastasis Rev 2003;22:465-72.
23. Baron MA. Structure of the intestinal peritoneum in man†. Dev Dyn 1941;69:439-97.

24. Brücher BL, Piso P, Verwaal V, et al. Peritoneal carcinomatosis: cytoreductive surgery and HIPEC-overview and basics. Cancer Invest 2012;30:209-24.

25. Sugarbaker PH. Peritoneum as the first-line of defense in carcinomatosis. J Surg Oncol 2007;95:93-6.

26. Kusamura S. Pathophysiology and biology of peritoneal carcinomatosis. World J Gastrointest Oncol 2010;2:12.

27. Biacchi D, Accarpio F, Ansaloni L, et al. Upfront debulking surgery versus interval debulking surgery for advanced tubo-ovarian high-grade serous carcinoma and diffuse peritoneal metastases treated with peritonectomy procedures plus HIPEC. J Surg Oncol 2019;120:1208-19.

28. Lim MC, Chang SJ, Yoo HJ, et al. Randomized trial of hyperthermic intraperitoneal chemotherapy (HIPEC) in women with primary advanced peritoneal, ovarian, and tubal cancer. J Clin Oncol 2017;35:5520.

29. Huober J, Meyer A, Wagner U, et al. The role of neoadjuvant chemotherapy and interval laparotomy in advanced ovarian cancer. J Cancer Res Clin Oncol 2002;128:153-60.

30. Ozols RF, Rubin SC, Thomas GM. Epithelial ovarian cancer. In: Principles and practice of gynecologic oncology. 1996:919-86.

31. Cannistra SA. Cancer of the ovary. N Engl J Med 2004;351:2519-29.

32. Polom K, Roviello G, Generali D, et al. Cytoreductive surgery and hyperthermic intraperitoneal chemotherapy for treatment of ovarian cancer. Int J Hyperthermia 2016;32:298-310.

33. Vergote I, Tropé CG, Amant F, et al. Neoadjuvant chemotherapy or primary surgery in stage IIIC or IV ovarian cancer. N Engl J Med 2010;363:943-53.

34. Cascales-Campos PA, Gil J, Gil E, et al. Treatment of microscopic disease with hyperthermic intraoperative intraperitoneal chemotherapy after complete cytoreduction improves disease-free survival in patients with stage IIIC/IV ovarian cancer. Ann Surg Oncol 2014;21:2383-9.

35. van Driel WJ, Koole SN, Sikorska K, et al. Hyperthermic Intraperitoneal Chemotherapy in Ovarian Cancer. N Engl J Med 2018;378:230-40.

36. Deraco M, Virzì S, Iusco DR, et al. Secondary cytoreductive surgery and hyperthermic intraperitoneal chemotherapy for recurrent epithelial ovarian cancer: a multi-institutional study. BJOG 2012;119:800-9.

37. Ryu KS, Kim JH, Ko HS, et al. Effects of intraperitoneal 
hyperthermic chemotherapy in ovarian cancer. Gynecol Oncol 2004;94:325-32.

38. Di Giorgio A, De Iaco P, De Simone M, et al. Cytoreduction (Peritonectomy Procedures) Combined with Hyperthermic Intraperitoneal Chemotherapy (HIPEC) in Advanced Ovarian Cancer: Retrospective Italian Multicenter Observational Study of 511 Cases. Ann Surg Oncol 2017;24:914-22.

39. de Bree E, Helm CW. Hyperthermic intraperitoneal chemotherapy in ovarian cancer: rationale and clinical data. Expert Rev Anticancer Ther 2012;12:895-911.

40. Cotte E, Glehen O, Mohamed F, et al. Cytoreductive surgery and intraperitoneal chemohyperthermia for chemoresistant and recurrent advanced epithelial ovarian cancer: Prospective study of 81 patients. World J Surg 2007;31:1813-20.

41. Rufián S, Muñoz-Casares FC, Briceño J, et al. Radical surgery-peritonectomy and intraoperative intraperitoneal chemotherapy for the treatment of peritoneal carcinomatosis in recurrent or primary ovarian cancer. J Surg Oncol 2006;94:316-24.

42. Fagotti A, Costantini B, Vizzielli G, et al. HIPEC in recurrent ovarian cancer patients: Morbidity-related treatment and long-term analysis of clinical outcome. Gynecol Oncol 2011;122:221-5.

43. Classe JM, Glehen O, Decullier E, et al. Cytoreductive Surgery and Hyperthermic Intraperitoneal Chemotherapy for First Relapse of Ovarian Cancer. Anticancer Res 2015;35:4997-5005.

44. Gonzalez Bayon L, Steiner MA, Vasquez Jimenez $W$, et al. Cytoreductive surgery and hyperthermic intraperitoneal chemotherapy for the treatment of advanced epithelial ovarian carcinoma: Upfront therapy, at first recurrence, or later? Eur J Surg Oncol 2013;39:1109-15.

45. Ansaloni L, Agnoletti V, Amadori A, et al. Evaluation of extensive cytoreductive surgery and hyperthermic intraperitoneal chemotherapy (HIPEC) in patients with advanced epithelial ovarian cancer. Int J Gynecol Cancer 2012;22:778-85.

46. Roviello F, Roviello G, Petrioli R, et al. Hyperthermic intraperitoneal chemotherapy for the treatment of ovarian cancer: A brief overview of recent results. Crit Rev Oncol Hematol 2015;95:297-305.

47. Muñoz-Casares FC, Medina-Fernández FJ, ArjonaSánchez, et al. Peritonectomy procedures and HIPEC in the treatment of peritoneal carcinomatosis from ovarian cancer: Long-term outcomes and perspectives from a high-volume center. Eur J Surg Oncol 2016;42:224-33.

48. Muñoz-Casares FC, Rufián S, Rubio MJ, et al. The role of hyperthermic intraoperative intraperitoneal chemotherapy (HIPEC) in the treatment of peritoneal carcinomatosis in recurrent ovarian cancer. Clin Transl Oncol 2009; 11:753-9.

49. Rietbroek RC, van de Vaart PJ, Haveman J, et al. Hyperthermia enhances the cytotoxicity and platinumDNA adduct formation of lobaplatin and oxaliplatin in cultured SW 1573 cells. J Cancer Res Clin Oncol 1997;123:6-12.

50. Teicher BA, Kowal CD, Kennedy KA, et al. Enhancement by hyperthermia of the in vitro cytotoxicity of mitomycin $\mathrm{C}$ toward hypoxic tumor cells. Cancer Res 1981;41:1096-9.

51. Yan TD. A pharmacological review on intraperitoneal chemotherapy for peritoneal malignancy. World J Gastrointest Oncol 2010;2:109.

52. Cotte E, Colomban O, Guitton J, et al. Population pharmacokinetics and pharmacodynamics of cisplatinum during hyperthermic intraperitoneal chemotherapy using a closed abdominal procedure. J Clin Pharmacol 2011;51:9-18.

53. Batista TP, Kusamura S. Comments on: Pharmacokinetics of cisplatin during open and minimally-invasive secondary cytoreductive surgery plus HIPEC in women with platinum-sensitive recurrent ovarian cancer: a prospective study. J Gynecol Oncol 2019;30:e111.

54. Armstrong DK, Bundy B, Wenzel L, et al. Intraperitoneal Cisplatin and Paclitaxel in Ovarian Cancer. N Engl J Med 2006;354:34-43.

55. Reinhold HS,Endrich B. Tumour microcirculation as a target for hyperthermia. Int J Hyperthermia 1986;2:111-37.

56. Fajardo LF. Pathological effects of hyperthermia in normal tissues. Cancer Res 1984;44:4826s-4835s.

57. Seegenschmiedt MH, Fessenden P, Vernon CC, editors. Thermoradiotherapy and Thermochemotherapy. Berlin, Heidelberg: Springer Berlin Heidelberg, 1995.

58. Dunlop PRC, Hand JW, Dickinson RJ, et al. An assessment of local hyperthermia in clinical practice. Int $\mathrm{J}$ Hyperthermia 1986;2:39-50.

59. Beaujard AC, Glehen O, Caillot JL, et al. Intraperitoneal chemohyperthermia with mitomycin $\mathrm{C}$ for digestive tract cancer patients with peritoneal carcinomatosis. Cancer 2000;88:2512-9.

60. Harmon RL, Sugarbaker PH. Prognostic indicators in peritoneal carcinomatosis from gastrointestinal cancer. Int Semin Surg Oncol 2005;2:3.

61. Verwaal VJ, van Tinteren H, Ruth SV, et al. Toxicity of 
cytoreductive surgery and hyperthermic intra-peritoneal chemotherapy. J Surg Oncol 2004;85:61-7.

62. Witkamp AJ, de Bree E, Kaag MM, et al. Extensive cytoreductive surgery followed by intra-operative hyperthermic intraperitoneal chemotherapy with mitomycin-C in patients with peritoneal carcinomatosis of colorectal origin. Eur J Cancer 2001;37:979-84.

63. Jacquet P, Sugarbaker PH. Clinical research methodologies in diagnosis and staging of patients with peritoneal carcinomatosis. Cancer Treat Res 1996;82:359-74.

64. Sugarbaker PH. Successful management of microscopic residual disease in large bowel cancer. Cancer Chemother Pharmacol 1999;43 Suppl:S15-25.

65. Tentes AAK, Tripsiannis G, Markakidis SK, et al. Peritoneal cancer index: A prognostic indicator of survival in advanced ovarian cancer. Eur J Surg Oncol 2003;29:69-73.

66. Foster JM, Sleightholm R, Smith L, et al. The American Society of Peritoneal Surface Malignancies MultiInstitution evaluation of 1,051 advanced ovarian cancer patients undergoing cytoreductive surgery and HIPEC: An introduction of the peritoneal surface disease severity score. J Surg Oncol 2016;114:779-84.

67. Pelz JOW, Stojadinovic A, Nissan A, et al. Evaluation of a peritoneal surface disease severity score in patients with colon cancer with peritoneal carcinomatosis. J Surg Oncol 2009;99:9-15.

68. Esquivel J, Lowy AM, Markman M, et al. The American Society of Peritoneal Surface Malignancies (ASPSM) Multiinstitution Evaluation of the Peritoneal Surface Disease Severity Score (PSDSS) in 1,013 Patients with Colorectal Cancer with Peritoneal Carcinomatosis. Ann Surg Oncol 2014;21:4195-201.

69. Bristow RE, Duska LR, Lambrou NC, et al. A model for predicting surgical outcome in patients with advanced ovarian carcinoma using computed tomography. Cancer 2000;89:1532-40.

70. Fagotti A, Ferrandina G, Fanfani F, et al. A laparoscopybased score to predict surgical outcome in patients with advanced ovarian carcinoma: A pilot study. Ann Surg Oncol 2006;13:1156-61.

71. Fagotti A, Fanfani F, Ludovisi M, et al. Role of laparoscopy to assess the chance of optimal cytoreductive surgery in advanced ovarian cancer: A pilot study. Gynecol Oncol 2005;96:729-35.

72. Fagotti A, Costantini B, Petrillo M, et al. Cytoreductive surgery plus HIPEC in platinum-sensitive recurrent ovarian cancer patients: A case-control study on survival in patients with two year follow-up. Gynecol Oncol 2012;127:502-5.

73. Warschkow R, Tarantino I, Lange J, et al. Does hyperthermic intraoperative chemotherapy lead to improved outcomes in patients with ovarian cancer? A single center cohort study in 111 consecutive patients. Patient Saf Surg 2012;6:12.

74. Bakrin N, Cotte E, Golfier F, et al. Cytoreductive surgery and hyperthermic intraperitoneal chemotherapy (HIPEC) for persistent and recurrent advanced ovarian carcinoma: A multicenter, prospective study of 246 patients. Ann Surg Oncol 2012;19:4052-8.

75. Bakrin N, Bereder JM, Decullier E, et al. Peritoneal carcinomatosis treated with cytoreductive surgery and Hyperthermic Intraperitoneal Chemotherapy (HIPEC) for advanced ovarian carcinoma: A French multicentre retrospective cohort study of 566 patients. Eur J Surg Oncol 2013;39:1435-43.

76. Raspagliesi F, Kusamura S, Campos Torres JC, et al. Cytoreduction combined with intraperitoneal hyperthermic perfusion chemotherapy in advanced/ recurrent ovarian cancer patients: The experience of National Cancer Institute of Milan. Eur J Surg Oncol 2006;32:671-5.

77. Bae JH, Lee JM, Ryu KS, et al. Treatment of ovarian cancer with paclitaxel- or carboplatin-based intraperitoneal hyperthermic chemotherapy during secondary surgery. Gynecol Oncol 2007;106:193-200.

78. Bereder J, Glehen O, Habre J, et al. Cytoreductive surgery combined with perioperative intraperitoneal chemotherapy for the management of peritoneal carcinomatosis from ovarian cancer: A multiinstitutional study of 246 patients. J Clin Oncol 2009;27:5542.

79. Pavlov MJ, Kovacevic PA, Ceranic MS, et al. Cytoreductive surgery and modified heated intraoperative intraperitoneal chemotherapy (HIPEC) for advanced and recurrent ovarian cancer - 12-year single center experience. Eur J Surg Oncol 2009;35:1186-91.

80. Chua TC, Robertson G, Liauw W, et al. Intraoperative hyperthermic intraperitoneal chemotherapy after cytoreductive surgery in ovarian cancer peritoneal carcinomatosis: systematic review of current results. J Cancer Res Clin Oncol 2009;135:1637-45.

81. Guardiola E, Delroeux D, Heyd B, et al. Intra-operative intra-peritoneal chemotherapy with cisplatin in patients with peritoneal carcinomatosis of ovarian cancer. World J Surg Oncol 2009;7:14.

82. Pomel C, Ferron G, Lorimier G, et al. Hyperthermic intra- 
peritoneal chemotherapy using Oxaliplatin as consolidation therapy for advanced epithelial ovarian carcinoma. Results of a phase II prospective multicentre trial. CHIPOVAC study. Eur J Surg Oncol 2010;36:589-93.

83. Tan WJ, Wong JF, Chia CS, et al. Quality of life after cytoreductive surgery and hyperthermic intraperitoneal chemotherapy: an Asian perspective. Ann Surg Oncol 2013;20:4219-23.

84. Chia CS, Tan GHC, Lim C, et al. Prospective Quality of Life Study for Colorectal Cancer Patients with Peritoneal Carcinomatosis Undergoing Cytoreductive Surgery and Hyperthermic Intraperitoneal Chemotherapy. Ann Surg Oncol 2016;23:2905-13.

85. Piso P, Glockzin G, von Breitenbuch P, et al. Quality of life after cytoreductive surgery and hyperthermic intraperitoneal chemotherapy for peritoneal surface malignancies. J Surg Oncol 2009;100:317-20.

86. Koole SN, Van Driel WJ, Sonke GS. Hyperthermic intraperitoneal chemotherapy for ovarian cancer: The heat is on. Cancer 2019;125:4587-93.

87. Moinpour CM, Feigl P, Metch B, et al. Quality of life end points in cancer clinical trials: review and recommendations. J Natl Cancer Inst 1989;81:485-95.

88. Roila F, Cortesi E. Quality of life as a primary end point in oncology. Ann Oncol 2001;12 Suppl 3:S3-6.

89. Perren TJ, Swart AM, Pfisterer J, et al. A phase 3 trial of bevacizumab in ovarian cancer. N Engl J Med 2011;365:2484-96.

90. Aghajanian C, Blank SV, Goff BA, et al. OCEANS: A randomized, double-blind, placebo-controlled phase III trial of chemotherapy with or without bevacizumab in patients with platinum-sensitive recurrent epithelial ovarian, primary peritoneal, or fallopian tube cancer. J

Cite this article as: Medina-Castro JM, Ruiz-DeLeón A. Role of hyperthermic intraperitoneal chemotherapy in ovarian cancer. Chin Clin Oncol 2020;9(4):44. doi: 10.21037/cco-20-49
Clin Oncol 2012;30:2039-45.

91. Cohn DE, Kim KH, Resnick KE, et al. At what cost does a potential survival advantage of bevacizumab make sense for the primary treatment of ovarian cancer? A costeffectiveness analysis. J Clin Oncol 2011;29:1247-51.

92. Guy H, Walder L, Fisher M. Cost-Effectiveness of Niraparib Versus Routine Surveillance, Olaparib and Rucaparib for the Maintenance Treatment of Patients with Ovarian Cancer in the United States. Pharmacoeconomics 2019;37:391-405.

93. Zhong L, Tran AT, Tomasino T, et al. Cost-effectiveness of niraparib and olaparib as maintenance therapy for patients with platinum-sensitive recurrent ovarian cancer. J Manag Care Spec Pharm 2018;24:1219-28.

94. Barnett JC, Alvarez Secord A, Cohn DE, et al. Cost effectiveness of alternative strategies for incorporating bevacizumab into the primary treatment of ovarian cancer. Cancer 2013;119:3653-61.

95. Chua TC, Martin S, Saxena A, et al. Evaluation of the cost-effectiveness of cytoreductive surgery and hyperthermic intraperitoneal chemotherapy (peritonectomy) at the st george hospital peritoneal surface malignancy program. Ann Surg 2010;251:323-9.

96. Lim SL, Havrilesky LJ, Habib AS, et al. Costeffectiveness of hyperthermic intraperitoneal chemotherapy (HIPEC) at interval debulking of epithelial ovarian cancer following neoadjuvant chemotherapy. Gynecol Oncol 2019;153:376-80.

97. Alberts DS, Markman M, Armstrong D, et al. Intraperitoneal therapy for stage III ovarian cancer: a therapy whose time has come! J Clin Oncol 2002;20:3944-6. 


\section{Appendix 1 List of ongoing HIPEC Clinical Trials}

1. Chang S, Lee J. Comparative Effectiveness of HIPEC Following Interval Debulking Surgery in Patients With Advanced-stage Ovarian Cancer [Internet]. Republic of Korea , july 2019: Ajou University School of Medicine; p. ClinicalTrials.gov identifier (NCT number): NCT03448354. Available online: https://clinicaltrials.gov/ ct2/show/NCT03448354?term=NCT03448354\&draw=2 \&rank $=1$

2. Cui S, Lin Z. Efficacy of HIPEC in the Treatment of Advanced-Stage Epithelial Ovarian Cancer After Cytoreductive Surgery (EHTASEOCCS) [Internet]. China, November 2019: Affiliated Cancer Hospital \& Institute of Guangzhou Medical University; p. ClinicalTrials.gov identifier (NCT number): NCT03373058, Other Study ID Numbers: HIPEC-03. Available online: https://clinicaltrials.gov/ct2/show/NCT0 3373058 ? term $=$ NCT03373058 \& draw $=2 \&$ rank $=1$

3. NARDUCCI F. Hyperthermic Intraperitoneal Chemotherapy (HIPEC) in Ovarian Cancer (CHIPPI) (CHIPPI) [Internet]. France, February 2019, multicentric: Centre Oscar Lambret; p. ClinicalTrials.gov identifier (NCT number): NCT03842982, Other Study ID Numbers: CHIPPI-1808 2018-003680-62 (EudraCT Number ). Available online: https://clinicaltrials.gov/ct2/ show/NCT03842982?term=NCT03842982\&draw $=2 \&$ ra $\mathrm{nk}=1$

4. Momeni M. Hyperthermic Intraperitoneal Chemotherapy for Recurrent Ovarian Cancer [Internet]. United States, California, March 2019: Loma Linda University,; p. ClinicalTrials.gov identifier (NCT number): NCT02672098, Other Study ID Numbers: 5150302. Available online: https://clinicaltrials.gov/ct2/show/NCT0 2672098? term=NCT02672098 \&draw $=2 \&$ rank $=1$

5. Jewell A. Heated Intraperitoneal Chemotherapy in Primary Ovarian Cancer Patients [Internet]. University of Kansas Medical Center, July 2019; p. ClinicalTrials.gov identifier (NCT number): NCT03321188, Other Study ID Numbers: IIT-2017-HIPEC-Ovarian. Available online: https://clinicaltrials.gov/ct2/show/NCT03321188?term= NCT03321188\&draw $=2 \&$ rank $=1$

6. Salcedo-Hernández R. HIPEC in Ovarian Carcinoma Clinical Stage IIIC and IV During Interval Laparotomy [Internet]. Mexico, September 2017: Instituto Nacional de Cancerologia de Mexico; p. ClinicalTrials.gov identifier (NCT number): NCT03275194, Other Study ID Numbers: INCAN/CI/483/15. Available online: https:// clinicaltrials.gov/ct2/show/NCT03275194?term=NCT03
$275194 \&$ draw $=2 \&$ rank $=1$

7. Lomnytska M, Graf W. Hyperthermic Intraperitoneal Chemotherapy for Treatment of Relapsed Ovarian Cancer [Internet]. Sweden, October 2018: Uppsala University Karolinska Institutet The Netherlands Cancer Institute; p. ClinicalTrials.gov identifier (NCT number): NCT03717610, Other Study ID Numbers: 077/2018. Available online: https://clinicaltrials.gov/ct2/show/NCT0 3717610? term $=$ NCT03717610\&draw $=2 \&$ rank $=1$

8. Diaz-Montes T, Sardi A. HOT: HIPEC in Ovarian Cancer as Initial Treatment (CRS/HIPEC) [Internet]. United States, Maryland, November 2019: Mercy Medical Center; p. ClinicalTrials.gov identifier (NCT number): NCT02124421, Other Study ID Numbers: MMC-201417. Available online: https://clinicaltrials.gov/ct2/show/ NCT02124421?term=NCT02124421\&draw $=2 \&$ rank $=1$

9. Whyte J. HIPEC After Initial CRS in Patients Who Have Received NACT [Internet]. United States, New York, July 2019: Northwell Health, Katie Oppo Foundation; p. ClinicalTrials.gov identifier (NCT number):

NCT03540017,. Available online: https://clinicaltrials.gov/ ct2/show/NCT03540017? term=NCT03540017\&draw $=2$ \&rank=1

10. Kelly M. Hyperthermic Intraperitoneal Chemotherapy or Intraperitoneal Chemotherapy in Comparing Quality of Life in Patients With Stage IIIC-IV Ovarian, Fallopian Tube, or Primary Peritoneal Cancer [Internet]. United States, North Carolina, November 2019: Wake Forest University Health Sciences Collaborator:,National Cancer Institute (NCI); p. ClinicalTrials.gov identifier (NCT number): NCT03188432, Other Study ID Numbers: IRB00044434. Available online: https://clinicaltrials.gov/ ct $2 /$ show/NCT03188432? term=NCT03188432\&draw $=2$ \&rank=1

11. Dellinger T. Surgery and Chemotherapy With or Without Chemotherapy After Surgery in Treating Patients With Ovarian, Fallopian Tube, Uterine, or Peritoneal Cancer [Internet]. United States, California, February 2020: City of Hope Medical Center National Cancer Institute (NCI); p. ClinicalTrials.gov identifier (NCT number): NCT01970722, Other Study ID Numbers: 12316 NCI-2013-01948 ( Registry Identifier: CTRP (Clinical Trial Reporting Program) ). Available online: https:// clinicaltrials.gov/ct2/show/NCT01970722?term=NCT01 $970722 \&$ draw $=2 \&$ rank $=1$

12. Kwon S, Schwegman J. Trial of Cytoreductive Surgery and HIPEC in Patients With Primary and Secondary Peritoneal Cancers [Internet]. United States, New Jersey, September 2019: Holy Name Medical 
Center, Inc.; p. ClinicalTrials.gov identifier (NCT number): NCT03604653, Other Study ID Numbers: holynameHIPEC1. Available online: https://clinicaltrials. gov/ct2/show/NCT03604653?term=NCT03604653\&dra $\mathrm{w}=2 \&$ rank $=1$

13. Lilja J, Bastidas A. Clinical Trial of Intraperitoneal Hyperthermic Chemotherapy (HIPEC/IPHC) [Internet]. United States, California, April 2019: Bay Area Gynecology Oncology; p. ClinicalTrials.gov identifier (NCT number): NCT02349958, Other Study ID Numbers: HIPEC. Available online: https://clinicaltrials. gov/ct2/show/NCT02349958?term=NCT02349958\&dra $\mathrm{w}=2 \& \mathrm{rank}=1$

14. Villarejo-Campos P, Redondo-Calvo J. Hyperthermic Intraperitoneal Chemotherapy With Paclitaxel in Advanced Ovarian Cancer (hipecova) [Internet]. Spain, August 2018: Hospital General de Ciudad Real University of Castilla-La Mancha; p. ClinicalTrials.gov identifier (NCT number): NCT02681432, Other Study ID Numbers: HGCRCIRU001. Available online: https:// clinicaltrials.gov/ct2/show/NCT02681432?term=NCT02 $681432 \&$ draw $=2 \&$ rank $=1$

15. Van Driel W. Secondary Debulking Surgery +/Hyperthermic Intraperitoneal Chemotherapy in Stage III Ovarian Cancer [Internet]. Netherlands, August 2018: The Netherlands Cancer Institute; p. ClinicalTrials.gov identifier (NCT number): NCT00426257, Other Study ID Numbers: M06OVH-OVHIPEC 2006-003466-34 ( EudraCT Number ). Available online: https://clinicaltrials. gov/ct2/show/NCT00426257?term=NCT00426257\&dra $\mathrm{w}=2 \&$ rank $=1$

16. CLASSE J. Hyperthermic Intra-Peritoneal Chemotherapy (HIPEC) in Relapse Ovarian Cancer Treatment (CHIPOR) [Internet]. Nantes, France, March 2019: Centre rené Gauducheau, NANTES, UNICANCER; p. ClinicalTrials.gov identifier (NCT number): NCT01376752, Other Study ID Numbers: FEDEGYN 02/0410-CHIPOR 2010-023035-42 (EudraCT Number). Available online: https://clinicaltrials.gov/ct2/show/NCT0 1376752? term=NCT01376752\&draw $=2 \&$ rank $=1$

17. Zivanovic O. Outcomes After Secondary Cytoreductive Surgery With or Without Carboplatin Hyperthermic Intraperitoneal Chemotherapy (HIPEC) Followed by
Systemic Combination Chemotherapy for Recurrent Platinum-Sensitive Ovarian, Fallopian Tube, or Primary Peritoneal Cancer [Internet]. United States, February 2020: Memorial Sloan Kettering Cancer Center Mayo Clinic Baptist Health South Florida Hartford HealthCare University of Pittsburgh University of Chicago; p. ClinicalTrials.gov identifier (NCT number): NCT01767675, Other Study ID Numbers: 12-275. Available online: https://clinicaltrials.gov/ct2/show/NCT0 1767675 ? term $=$ NCT0 $1767675 \&$ draw $=2 \&$ rank $=1$

18. Ceelen W. Intraoperative Intraperitoneal Chemoperfusion to Treat Peritoneal Minimal Residual Disease in Stage III Ovarian Cancer (OvIP1) [Internet]. Belgium, UZ ghent, January 2019: University Hospital, Ghent; p. ClinicalTrials.gov identifier (NCT number): NCT02567253,. Available online: https://clinicaltrials.gov/ ct $2 /$ show/NCT02567253?term $=$ NCT02567253\&draw $=2$ \&rank=1

19. Cascales-Campos P. Cytoreduction With or Without Intraoperative Intraperitoneal Hyperthermic Chemotherapy (HIPEC) in Patients With Peritoneal Carcinomatosis From Ovarian Cancer, Fallopian Tube or Primary Peritoneal Carcinoma (CARCINOHIPEC) [Internet]. Fundacion para la Formacion e Investigacion Sanitarias de la Region de Murcia; p. ClinicalTrials.gov identifier (NCT number): NCT02328716, Other Study ID Numbers: EC-GC/AD-01/11 2011-001715-31 ( EudraCT Number ). Available online: https://clinicaltrials. gov/ct2/show/NCT02328716? term=NCT02328716\&dra $\mathrm{w}=2 \&$ rank $=1$

20. Ansaloni L. Phase 3 Trial Evaluating Hyperthermic Intraperitoneal Chemotherapy in Upfront Treatment of Stage IIIC Epithelial Ovarian Cancer (CHORINE) [Internet]. Germany, Italy, february 2014: A.O. Ospedale Papa Giovanni XXIII, Clinical Organization for Strategies \& Solutions (CLIOSS), former Nerviano Medical Sciences (http://www.nervianoms.com/en/) Onlus Cancro Primo Aiuto (http://www.cpaonlus.it/); p. ClinicalTrials.gov identifier (NCT number): NCT01628380, Other Study ID Numbers: CHORINE 2012-002616-22. Available online: https://clinicaltrials.gov/ct2/show/NCT01628380? term $=$ NCT0 $1628380 \&$ draw $=2 \&$ rank $=1$ 